\title{
DESAFIOS E PERSPECTIVAS ATUAIS NA FORMAÇÃO DO PROFESSOR DE QUÍMICA: EXPECTATIVAS SOBRE O MESTRADO PROFISSIONAL EM QUÍMICA EM REDE NACIONAL (PROFQUI)
}

\author{
Glaucia R. Gonzaga ${ }^{a, b, *,(1), ~ D a n i e l ~ C . ~ d e ~ P a i v a ~}{ }^{\mathrm{b}}$ e Marcelo L. Eichler ${ }^{\mathrm{a}}$ \\ aDepartamento de Bioquímica, Instituto de Biociências, Universidade Federal do Rio Grande do Sul, 90035-003 Porto Alegre - \\ RS, Brasil \\ bDepartamento de Ciências Exatas, Biológicas e da Terra, Instituto do Noroeste Fluminense de Educação Superior, Universidade \\ Federal Fluminense, 28470-000 Santo Antônio de Pádua - RJ, Brasil
}

Recebido em 17/09/2019; aceito em 11/12/2019; publicado na web em 12/03/2020

\begin{abstract}
CHALLENGES AND CURRENT PERSPECTIVES ON CHEMISTRY TEACHERS FORMATION: EXPECTATIONS ABOUT PROFESSIONAL MASTER IN CHEMISTRY IN NATIONAL NETWORK (PROFQUI). In Brazil, the continuing education of chemistry teachers has recently begun to form part of a broader public policy: the Professional Master Programs for the Qualification of Teachers of the Public Basic School (ProEB). The overall objective of these programs would be to contribute to the professional development by conducting qualified and current research that seeks to improve professional practices. Specifically, this article aims to present the perceptions of students and teachers in the initial phase of implementation of the Professional Master of Chemistry in National Network (PROFQUI). In this sense, the following are addressed: a) the aspects of teacher education in undergraduate chemistry courses; b) the continuing education of these teachers; c) the proposal of the professional masters, with special attention to PROFQUI; d) the initial data from a longitudinal survey involving 44 chemistry teachers and 27 university professors, collected from 6 higher education institutions participating in the PROFQUI. In short, it can be concluded that teachers of basic education seek from their professional development to improve the teaching of school chemistry. In this sense, such intended improvements are not only about scientific updating in chemistry, but also about didactic resources and possible practices and activities that contribute to their professional performance.
\end{abstract}

Keywords: teachers education; chemistry teaching; curricular innovation; postgraduate studies.

\section{INTRODUÇÃO}

Os documentos norteadores da educação básica nacional indicam a necessidade e importância da formação de alunos através de um processo educacional contextualizado, interdisciplinar e inclusivo (do ponto de vista social, tecnológico e ambiental). Para possibilitar a formação desse aluno proativo e engajado é preciso que o professor se paute não apenas na qualidade do conhecimento técnico a ser construído dentro das ditas "áreas brutas” (como Química, Biologia, Matemática, História, dentre outras), mas também na consciência e qualidade de sua prática/ação e no planejamento pedagógico a ser empregado no processo educacional.

É indiscutível a importância do papel do professor para um efetivo aprendizado de qualidade e solidez, mesmo que essa aprendizagem seja atribuída às ações e às estruturas dos alunos. ${ }^{1}$ Nesse sentido é essencial que esses professores estejam/sejam "familiarizados" com os processos de construção do conhecimento, seja para possibilitar aos alunos uma efetiva ação de elaboração conceitual, seja para incentivar reflexões críticas sobre as abordagens didáticas a serem utilizadas na sua rotina escolar. ${ }^{2}$ As atividades a serem desenvolvidas pelos professores devem proporcionar discussões construtivas em sala de aula, para que as concepções cotidianas e de senso comum dos alunos sejam confrontadas, refletidas e reelaboradas em direção de uma compreensão científica dos conteúdos escolares. ${ }^{1,3,4}$ Essa prática só é possível se o professor for formado para refletir e orquestrar essa construção significativa; e é sobre essa prática que vários grupos de pesquisa e Instituições de Ensino Superior (IES) têm empenhado esforços, pesquisas e discussões, visando à efetiva mudança no ensino escolar de Química.

*e-mail: glauciargonzaga@gmail.com
O objetivo desta pesquisa foi analisar as percepções de discentes e docentes acerca do Mestrado Profissional de Química em Rede Nacional (PROFQUI) na fase inicial de sua implementação. Cabe registrar que essa ação de formação continuada de professores de química está inserida no âmbito de uma política pública mais ampla: os Programas de Mestrado Profissional para Qualificação de Professores da Rede Pública de Educação Básica (ProEB). Dessa forma, este artigo tratará: aspectos da formação docente em cursos de licenciaturas em Química; a formação continuada desses professores; a proposta dos mestrados profissionais, com especial atenção ao PROFQUI; e apresentará os dados iniciais de uma pesquisa longitudinal em desenvolvimento coletados em seis Instituições de Ensino Superior (IES) que aderiram ao PROFQUI, bem como as perspectivas de desenvolvimento dessa pesquisa.

\section{A IMPORTÂNCIA DA FORMAÇÃO DOCENTE EM QUÍMICA}

Sobre a importância da formação docente para a Educação Básica no Brasil, Ghedin, Almeida e Leite ${ }^{5}$ colocam que a formação docente é um dos principais fatores para que uma escola atinja o nível de qualidade de ensino que tanto almejam os documentos norteadores da educação básica. Também se sugere que os alunos que apresentam êxito em sua formação docente, além das questões relacionadas a afetividade com base na teoria walloniana, ${ }^{6}$ faz uso (claro e planejado) de processos e recursos pedagógicos eficientes, contextualizados, inclusivos, dinâmicos e relevantes para o cotidiano escolar e a realidade da comunidade. Porém, a construção desse professor capaz de resolver todos, ou quase todos, os problemas da sala de aula da educação básica, possui entraves históricos fortemente atrelados ${ }^{7-11}$ que ainda não foram sanados pelas políticas públicas educacionais e que não 
compete apenas ao professor sozinho resolver. Essa construção é um processo constante e se baseia no processo de escolarização desse professor. Schnetzler ${ }^{12}$ coloca que os futuros professores já iniciam seus cursos de licenciatura com uma ideia simples e ingênua, advinda de experiências pessoais com seus professores da educação básica, de que para ser professor "basta conhecer o conteúdo e utilizar algumas técnicas pedagógicas" (p. 16).

Durante muitos anos essa ideia simplista foi sustentada pelo modelo tradicional de formação de professores, pautado unicamente na racionalidade técnica e conteudista. Porém, o processo de formação docente já passou por diversas mudanças ${ }^{7,13,14}$ em diversos aspectos, e ainda continua sendo alterado, seja com relação ao conteúdo abordado (atualização do conhecimento científico da área específica de formação) ou com a didática aplicada e construída (o preparo didático do docente para atuar de forma dinâmica, inclusiva e contextualizada no cenário social e tecnológico da sociedade). O foco desse processo deve ser a melhoria da prática profissional, para aumentar a contribuição na resolução de problemas e atendimento às demandas cotidianas. Parte da dificuldade de auto-avaliação do docente pode estar relacionada ao processo de "imitação" que os licenciandos fazem de seus professores. Se essa imitação permite desencadear uma reflexão crítica, com consequente mudança epistemológica, há questões diversas da subjetividade da construção da identidade docente. ${ }^{15,16} \mathrm{~A}$ construção dessa identidade é um processo que deveria ser visto como contínuo e continuado, enfatizando o estímulo ao pensamento crítico e o incentivo à atualização profissional crítica condizente com diversidade de realidades escolares.

\section{FORMAÇÃO CONTINUADA DE PROFESSORES}

Salvo experiências esparsas, as formas de ensino usadas nas escolas e na formação docente não suprem as necessidades da atual sociedade da tecnologia e da comunicação. ${ }^{17}$ Como colocado por Imbernón, ${ }^{13}$ "sente-se necessidade de uma nova forma de ver a educação, a formação e o papel dos professores e dos alunos” (p. 23).

Uma concepção que marcou por muito tempo a definição de cursos de formação continuada é que eles são unicamente complementos da formação em nível de graduação dos professores, ${ }^{18,19}$ uma forma de remediar as falhas da graduação. Essa concepção é indevida, uma vez que, quando devidamente planejada e executada, a formação continuada pode contribuir direta e efetivamente na prática profissional do indivíduo. A formação continuada, de acordo com $\operatorname{Schnetzler~}^{12}$ (p. 2)

[...] é um processo de aprendizagem e de socialização, de natureza voluntária, informal e pouco previsível que está centrado na interação entre colegas e nos problemas que trazem de suas práticas docentes. Por isso, um processo de formação continuada não é linear, mas sim sofre redefinições de rumos dependendo das necessidades de seus participantes.

A qualidade do ensino, de acordo com Wang et al. ${ }^{20}$ baseia-se em três pontos: i) o cognitivo, relacionado ao conhecimento e ações que os docentes levam da vida pessoal para a atuação profissional; ii) o performático, relacionado diretamente à prática docente e influenciado por suas experiências dentro e fora de sala de aula; e iii) o qualitativo, que corresponde aos resultados da aprendizagem independentemente de como esta é avaliada. O professor, como sujeito capaz de melhorar os processos de ensino e de aprendizagem, deve se tornar não apenas um colaborador/incentivador da construção do conhecimento, mas também um pesquisador pedagógico para melhoria da educação, ${ }^{21,22}$ estudando o seu cotidiano profissional, suas atividades e as sugestões de outros pesquisadores para o processo pedagógico, e sendo valorizado como um produtor de saberes pedagógicos e um profissional qualificado para enfrentar as diferentes situações escolares. De acordo com Machado ${ }^{23}$ (p. 170), o "professor-educador deve assumir a responsabilidade ética de ser um agente de mudanças no seu ambiente de trabalho, transformando-se num multiplicador de ideias"; porém, é necessário que as escolas onde eles atuem, os apoiem, os incentivem e os impulsionem, oferecendo tempo e espaço para que as discussões e atividades ocorram.

Quanto às possibilidades, Pena ${ }^{24}$ analisou uma proposta de formação continuada no Brasil e notou que os programas oferecidos à época eram iniciativas de Universidades, Secretarias de Educação, Superintendências Regionais de Ensino, escolas particulares, empresas de consultoria, além do próprio Ministério da Educação, que desenvolviam para/com os professores diferentes cursos, seminários, congressos e encontros pedagógicos envolvendo discussões sobre concepções pedagógicas e metodológicas. Bons exemplos de formação continuada para professores que já findaram são o PROMÉDIO (Programa Piloto de Inovação Curricular e de Capacitação Docente para o Ensino Médio), que foi um programa da Secretaria de Estado da Educação de Minas Gerais iniciado em 1997 para trazer aos professores novas orientações curriculares, atuando na "capacitação docente" até 1999;25 o PROCIÊNCIAS (Programa de Apoio ao Aperfeiçoamento de Professores de $2^{\circ}$ Grau em Matemática e Ciências), que foi um programa desenvolvido entre 1995 e 2001, era oferecido em vários estados, a partir de um convênio entre a CAPES, a Secretaria de Estado de Ciências e Tecnologia e as Secretaria de Educação dos diversos estados participantes, ${ }^{26}$ para promover o aperfeiçoamento dos professores de Matemática, Física, Química e Biologia. Um bom exemplo de formação continuada ainda em desenvolvimento é o ProEB (Programa para a Qualificação de Professores da Rede Pública de Educação Básica), ${ }^{27}$ que tem por objetivo promover a melhoria da qualidade do ensino nas escolas da Educação Básica Pública Brasileira através da

[...] a formação continuada stricto sensu dos professores em exercício na rede pública de educação básica, em conformidade com a política do Ministério da Educação - MEC, mediante apoio às instituições de ensino superior (IES) ou rede de instituições associadas do País, responsáveis pela implantação e execução de cursos com áreas de concentração e temáticas vinculadas diretamente à melhoria da Educação Básica.

Dentre os vários tipos de formação continuada, um que vem ganhando espaço é o Mestrado Profissional (MP), que está instituído dentro do ProEB, e é promovido por Instituições de Ensino Superior (IES) "de notória tradição na área de formação de professores e que sejam partícipes do Sistema Universidade Aberta do Brasil". ${ }^{28}$ Diferente do que ocorre com os Mestrados Acadêmicos (MAs), cujo enfoque é a construção de conhecimento técnico sobre uma área do conhecimento científico, nos MPs ${ }^{29,30}$ se busca aproximar a produção acadêmica das atividades laborais da sociedade. ${ }^{31,32}$

O enfoque e investimento da CAPES nos MP, de acordo com Ribeiro $^{33}$ (p. 1), possui três motivos baseados no desenvolvimento social e econômico do país: (i) "a sociedade atual requer uma formação cada vez mais qualificada, mesmo para setores que não lidam com a docência nem com a pesquisa de ponta"; (ii) "com o aumento das titulações no País, constata-se que boa parte dos mestres e uma parte significativa dos doutores encaminham-se para um destino que não é o ensino superior"; (iii) "a inexistência de preconceito da Capes quanto à transferência de conhecimento científico para as empresas ou para o mercado, desde que a sociedade como um todo, e o setor público e os movimentos sociais em particular, também sejam alvo dessa transferência". Por esses três motivos acredita-se que a CAPES facilita e investe na aplicação prática dos conhecimentos científicos fora das IES (a proposta central dos MP). 
Um MP voltado para a formação docente tem como foco preparar os docentes para atuação na dinâmica escolar, melhorando didaticamente a atuação de um professor da educação básica e fazendo com que este investigue e evolua dentro do seu próprio meio profissional. ${ }^{34,35}$ É um espaço propositivo de construção e aprofundamento das relações entre universidade e escola. Porém, é necessário que haja "uma reflexão aprofundada sobre a natureza do Mestrado Profissional [...] e seu impacto na sociedade" (p. 69) para que seus resultados sejam efetivos. ${ }^{36}$

De acordo com Nunes, ${ }^{37}$ um MPE, bem como um MP para formação docente, possui um cenário potencial para a efetiva qualificação dos professores da Educação Básica, pois busca: (i) a motivação dos professores; (ii) a compreensão desses a respeito do papel de um MP; (iii) a contribuição que as experiências vividas no MP podem proporcionar às práticas docentes cotidianas; $\mathrm{e}$ (iv) aumento do alcance e o fluxo de saberes entre a universidade e a escola. $\mathrm{O}$ auxílio, portanto, é justamente o de proporcionar a pesquisa dentro da formação docente como elemento articulador e colaborativo em vários pontos do processo educacional e da plena atuação profissional.

Os últimos dados da CAPES $^{38}$ indicam a existência de 589 cursos de pós-graduação, sendo 38 programas relativos a MP, distribuídos nas 5 regiões do Brasil. ${ }^{42}$ A CAPES recomenda programas "profissionais" nas várias áreas do conhecimento, como o: Mestrado Profissional em Matemática em Rede Nacional (PROFMAT); Programa de Mestrado Nacional Profissional em Ensino de Física (MNPEF/PROFIS); Programa de Mestrado Profissional em Letras (PROFLetras); Programa de Mestrado Profissional em Artes (PROFArtes); Programa de Mestrado Profissional em História (PROFHistória); Programa de Mestrado Profissional em Administração (PROFIAP); Mestrado Profissional em Saúde da Família (PROFSaúde); Mestrado Profissional em Educação Física (ProEF); Mestrado Profissional em Administração Pública (ProfiAP); Mestrado Profissional em Gestão e Regulação de Recursos Hídricos (ProfÁgua); Mestrado Profissional em Ensino de Ciências Ambientais (ProfCiamb) e o mais novo Programa de Mestrado Profissional em Química em Rede Nacional (PROFQUI). ${ }^{39}$

Com a amplitude das áreas de atuação dos MPs, como uma forma de compreender as finalidades (público alvo e contribuição) destes, Fischer ${ }^{31}$ sugere a divisão desses cursos em três grupos distintos: os Generalistas (qualificação profissional em nível estratégico, como os cursos da área de Administração), os Focalizados (qualificação profissional em setores específicos, onde o foco sejam tecnologias e de políticas públicas, como Engenharias e Odontologia), e os do tipo Híbrido (formado a partir da hibridização dos dois anteriores e gerando os MPs em Ensino, e tendo como alvo a prática profissional docente). Em todos estes, os mestrandos, seguindo as orientações das portarias supracitadas, apresentam suas dissertações desenvolvidas sobre um produto final que deve ser aplicável em sua atividade laboral. As possibilidades de trabalhos a serem desenvolvidos abrangem: dissertação como a desenvolvida em um MA, revisão de literatura, artigo cientifico, registro de patente, registro de propriedade intelectual, projeto técnico, aplicativos, programas de mídias, editoria, composição, concerto, relatório técnico, manual de operação técnica, protocolo de serviço, protocolo experimental, proposta de intervenção clínica, projeto de aplicação/adequação tecnológica, protótipo de instrumentos/equipamentos, produção artística, ou outros previamente aprovados pela CAPES..$^{40,41}$

\section{O PROGRAMA DE MESTRADO PROFISSIONAL EM QUÍMICA EM REDE NACIONAL (PROFQUI)}

O PROFQUI é um programa de MP formado por uma rede de IES, no contexto da UAB/CAPES (Universidade Aberta do Brasil/Coordenação de Aperfeiçoamento de Pessoal de Nível).
A coordenação desta rede nacional é realizada pelo Instituto de Química (IQ) da Universidade Federal do Rio de Janeiro (UFRJ), juntamente com a Sociedade Brasileira de Química (SBQ), e conta com a colaboração de um comitê gestor composto por docentes das IES associadas. Trata-se de um programa reconhecido pelo Conselho Nacional de Educação (CNE) e recomendado pela CAPES, com nota 4,0 na Avaliação Quadrienal 2017, desenvolvida pela CAPES e realizada pelo Ministério de Educação (MEC)..$^{37,42,43}$

O objetivo do programa é contribuir com a formação continuada em Química, com pesquisas atuais e qualificadas, para contribuir com a prática profissional dos docentes em exercício na educação básica nacional através do desenvolvimento do conhecimento científico. Assim como os demais MPs, o PROFQUI estimula pesquisas, bem como a produção de produtos e materiais didáticos, que estejam diretamente ligados com a realidade e o cotidiano escolar. Para tal, o programa disponibiliza editais anuais de seleção (Exame Nacional de Acesso ao Programa), para docentes atuantes na educação básica, em suas IES associadas. ${ }^{43}$

O PROFQUI funciona dentro do que estabelece a Lei ${ }^{\circ}$ 13.005/2014 do Plano Nacional de Educação (PNE), ${ }^{44}$ e tem como uma de suas diretrizes, apresentadas em seu artigo $2^{\circ}$, a valorização dos profissionais de educação. A Lei $13.005 / 2014^{44}$ coloca que um dos objetivos é

[...] formar, em nível de pós-graduação, 50\% (cinquenta por cento) dos professores da educação básica, até o último ano de vigência deste PNE, e garantir a todos (as) os (as) profissionais da educação básica formação continuada em sua área de atuação, considerando as necessidades, demandas e contextualizações dos sistemas de ensino.

Vários autores ${ }^{28,45-49}$ concordam com essa linha de pensamento, uma vez que a qualidade do ensino (em todas as suas extensões) está diretamente relacionada com a valorização docente (através da melhoria em sua formação em nível de graduação e formação continuada, condições de trabalho, plano de carreira e salário). Desdobramentos do PNE posteriores ao início desta pesquisa (da aplicação dos questionários de levantamento de dados) foram desconsideradas para este artigo.

Atualmente o PROFQUI possui 18 polos regionais, distribuídos em 11 estados (Figura 1), que seguem as especificações estabelecidas pelos coordenadores nacionais da UFRJ juntamente com o conselho geral/gestor (formado por 09 docentes das IES participantes - a saber, 03 da UFRJ, 01 da UFPR, 01 da UFF, 01 da UFAL, 01 da UFRN, 01 da UFRGS, e 01 da UFV), porém, adequando-se as suas especificidades regionais. ${ }^{43}$

Cada polo regional possui uma coordenação responsável pela administração do Programa em sua unidade; porém, as coordenações locais seguem um mesmo regimento para padronizar ações e procedimentos, visando a qualidade de ensino em todo o território nacional. Esse regimento ${ }^{43}$ aborda aspectos como os objetivos do programa, sua organização, a forma de ingresso de discentes, as normas para constituição do corpo docente, e especificações sobre a adesão de novas IES.

Além do Regimento, também foram estabelecidas as disciplinas obrigatórias a serem ministradas nas IES, para garantir que o programa cumpra as metas e objetivos estabelecidos na Lei 13.005/2014, e que tenha uma padronização mínima sem desconsiderar as especificidades regionais e pessoais dos docentes e discentes. Os discentes precisam cumprir a carga horária (C.H.) apresentada no Quadro 1.

Além das informações apresentadas na Tabela 1, a matriz curricular do programa também apresenta os objetivos do mesmo, o perfil do profissional por ele formado e uma breve descrição da oferta do curso. 

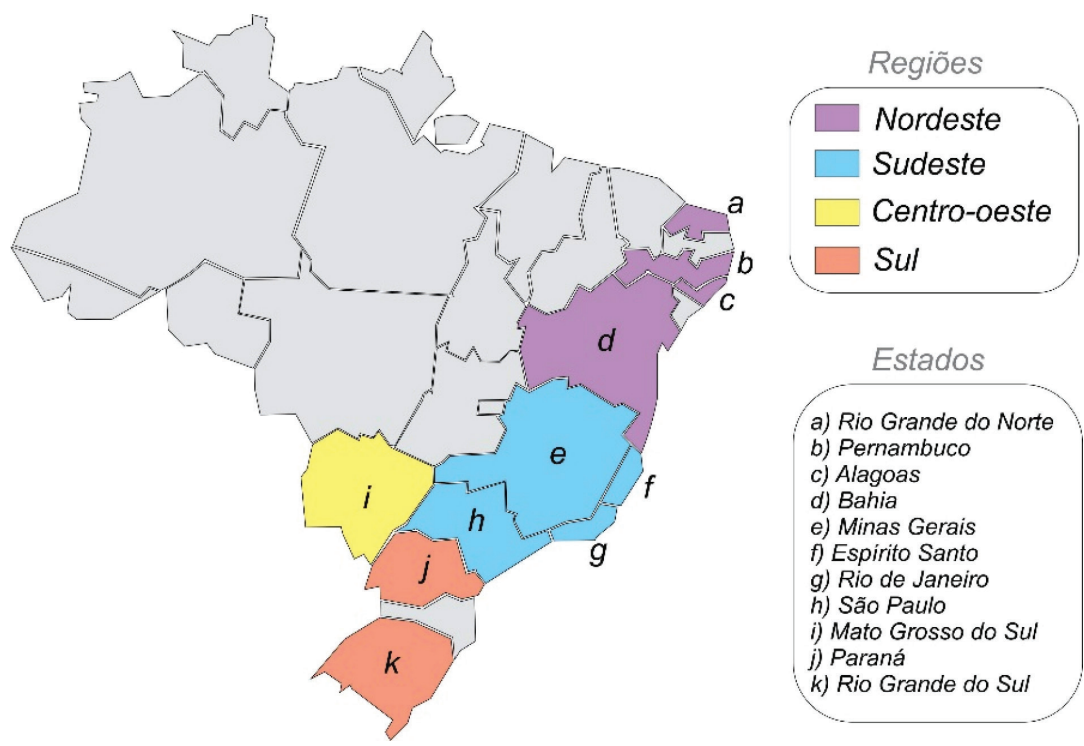

Figura 1. Estados que possuem polos regionais do PROFQUI

Quadro 1. Matriz curricular do PROFQUI

\begin{tabular}{|c|c|c|c|}
\hline Caráter & Atividade / Disciplina & Objetivo & Créditos / C.H. Total \\
\hline \multirow{4}{*}{ Disciplina Obrigatória } & Químicas 1, 2 e 3 (180 h) & $\begin{array}{l}\text { Atualização quanto ao conteúdo específico de } \\
\text { Química }\end{array}$ & \multirow{4}{*}{$24 / 360 \mathrm{~h}$} \\
\hline & $\begin{array}{l}\text { Abordagens Tecnológicas } \\
\text { Atualizadas no Ensino }(60 \mathrm{~h})\end{array}$ & $\begin{array}{l}\text { Relacionada ao desenvolvimento dos } \\
\text { fundamentos teóricos e metodológicos no uso } \\
\text { de tecnologias [ferramentas] computacionais } \\
\text { e de comunicação, e desenvolvimento de kits } \\
\text { para uso em sala de aula }\end{array}$ & \\
\hline & $\begin{array}{l}\text { Fundamentos Metodológicos para } \\
\text { a Pesquisa em Ensino de Química } \\
\qquad(60 \mathrm{~h})\end{array}$ & $\begin{array}{l}\text { Visando os Fundamentos Metodológicos para } \\
\text { a Pesquisa em Ensino de Química }\end{array}$ & \\
\hline & Seminários Web 1, 2, 3 e 4 (60h) & $\begin{array}{c}\text { Visa discutir aspectos didático-pedagógicos, } \\
\text { destacando visões contemporâneas de ensino, } \\
\text { aprendizagem e avaliação com foco no Ensino } \\
\text { da Química }\end{array}$ & \\
\hline \multirow[b]{2}{*}{ Atividades } & $\begin{array}{c}\text { Pesquisa de Dissertação de } \\
\text { Mestrado }\end{array}$ & $\begin{array}{c}\text { Estimular o desenvolvimento da pesquisa e da } \\
\text { escrita da dissertação }\end{array}$ & $24 / 360 \mathrm{~h}$ \\
\hline & Equivalência hora/aula & $\begin{array}{c}\text { Correspondem a atuação deste discente/ } \\
\text { docente em sua unidade escolar e visa } \\
\text { estimular a pesquisa através da prática } \\
\text { profissional }\end{array}$ & $15 /$ n.i. $^{a}$ \\
\hline
\end{tabular}

${ }^{a}$ n.i. = não informado.

Com relação as Linhas de Pesquisa (LPs) possíveis, as mesmas se distribuem entre conhecimento químico específico e desenvolvimento didático-pedagógico docente (Quadro 2), porém, todas apresentam alguma possibilidade de relacionada a produção e/ou análise de recursos didáticos de variados tipos, bem como a promoção da divulgação científica, a proposta de trabalho interdisciplinar e contextualizado, e metodologias diversificadas para o processo de ensino de Química.

Como outros Programas de mestrado, o PROFQUI também possui bolsas de estudo concedidas pela CAPES a discentes. A concessão dessas bolsas possui normas para que a seleção dos bolsistas contemple aqueles que cumprem as exigências estabelecidas pela CAPES. Dados os atuais acontecimentos de cortes financeiros dentro da CAPES, a concessão dessas bolsas pode deixar de ser uma realidade para o Programa.

\section{O PROFQUI FRENTE AOS OUTROS MPs DE FORMAÇÃO DOCENTE}

Todos os MPs voltados para a formação do docente, por sua natureza, têm características comuns: o foco para a pesquisa associada a atividade laboral relacionada à educação básica; a forma de ingresso se dá através de um exame nacional de acesso realizado anualmente; o desenvolvimento de um produto final obrigatório, aplicável à realidade profissional do participante. O que os diferencia um do outro são as inúmeras peculiaridades. Neste sentido, aqui se apresentam dados e levantamentos preliminares, mas que possibilitam identificar diferenças importantes (Tabela 1) e o potencial do presente trabalho por estar começando juntamente com o início do PROFQUI.

Comparado com outros MPs de mesma finalidade, como pode ser visto na Tabela 1, o início do PROFQUI é concomitante com o início da pesquisa longitudinal na qual este artigo se insere, e é um dos mais recentemente implantados. A baixa quantidade de vagas indica uma alta possibilidade de crescimento e se explica por questões de divulgação (devido ao início recente), além da proposta de começar aos poucos, consolidar e atuar para crescimento permanente.

A proposta central e inicial deste MP é que as pesquisas desenvolvidas promovam a reflexão do docente sobre algum problema educacional real dentro do ensino de Química, enquanto possibilita 
Quadro 2. Linhas de pesquisa do PROFQUI

\begin{tabular}{|c|c|c|c|}
\hline Linha de pesquisa & Título & Objetivo & $\begin{array}{l}\text { Quantidade de docentes } \\
\text { vinculados }\end{array}$ \\
\hline LP1 & $\begin{array}{l}\text { Novas tecnologias e } \\
\text { comunicação }\end{array}$ & $\begin{array}{l}\text { Produção e utilização das tecnologias da informação e comu- } \\
\text { nicação e da evolução tecnológica nos processos de formaça, } \\
\text { ensino e aprendizagem. } \\
\text { Divulgação científica como um dos aspectos centrais da produção } \\
\text { dos saberes científicos. } \\
\text { Produzir materiais multimídias de natureza didático-pedagógico } \\
\text { que contribuam para melhor desempenho das atividades de } \\
\text { divulgação e de ensino de química. }\end{array}$ & 4 \\
\hline LP2 & $\begin{array}{c}\text { Química ambiental e } \\
\text { energia }\end{array}$ & $\begin{array}{l}\text { Investiga as dimensões históricas, culturais e novas abordagens } \\
\text { de cunho científico, teórico e experimental, dos processos am- } \\
\text { bientais e energéticos em geral. } \\
\text { Estuda as formas de relação da química como o ambiente, em } \\
\text { confluência com a tecnologia. } \\
\text { Desenvolver e avaliar projetos de produtos e processos voltados } \\
\text { para o uso em sala de aula, laboratório e espaços não formais. }\end{array}$ & 6 \\
\hline LP3 & Química da vida & $\begin{array}{l}\text { Investiga as dimensões históricas, culturais e novas abordagens de } \\
\text { cunho científico, teórico e experimental, da química dos produtos } \\
\text { naturais, fármacos e processos biológicos. } \\
\text { Estuda as formas de relação da química com outras disciplinas, } \\
\text { tais como a Biologia e a Ciência de Alimentos, na dimensão do } \\
\text { Ensino Básico. } \\
\text { Procura desenvolver projetos e dinâmicas multidisciplinares } \\
\text { voltadas para o uso em sala de aula, laboratório e espaços não } \\
\text { formais. }\end{array}$ & 10 \\
\hline LP4 & Novos materiais & $\begin{array}{l}\text { Investiga as dimensões históricas, culturais e novas abordagens } \\
\text { de cunho científico, teórico e experimental, da química dos } \\
\text { novos materiais e dos processos de inovação, seus impactos } \\
\text { sociais, riscos e limitações em suas diferentes dimensões na } \\
\text { contemporaneidade. } \\
\text { Estuda formas de relação da química com outras disciplinas, tais } \\
\text { como a Física e a Matemática, na dimensão do Ensino Básico. } \\
\text { Desenvolver projetos e dinâmicas multidisciplinares voltadas } \\
\text { para o uso em sala de aula, laboratório e espaços não formais, } \\
\text { além de e avaliar e propor materiais didáticos. }\end{array}$ & 7 \\
\hline
\end{tabular}

a informações disponíveis na página do Programa Nacional.

Tabela 1. Comparativo entre mestrados profissionais de diferentes áreas

\begin{tabular}{lcccccccc}
\hline Área do MP & $\begin{array}{c}\text { IES } \\
\text { Participantes }\end{array}$ & $\begin{array}{c}\text { Vagas } \\
\text { ofertadas } \\
\text { em 2018 }\end{array}$ & $\begin{array}{c}\text { Quantidade } \\
\text { vagas por } \\
\text { IES }\end{array}$ & Coordenação & $\begin{array}{c}\text { Avaliação } \\
\text { da CAPES }\end{array}$ & $\begin{array}{c}\text { Ano de } \\
\text { início }\end{array}$ & $\begin{array}{c}\text { Dissertações } \\
\text { defendidas }\end{array}$ & Sitio eletrônico \\
\hline Química & 26 & $417^{\mathrm{e}}$ & 8 & SBQ+UFRJ & 4 & 2017 & - & https://profqui.iq.ufrj.br/ \\
Matemática & 100 & 1785 & 18 & SBM+IMPA & 5 & 2010 & 3654 & http://www.profmat-sbm.org.br/ \\
Física & 63 & $694^{\mathrm{a}}$ & 11 & SBF & 4 & 2013 & 319 & http://www1.fisica.org.br/mnpef/ \\
Letras & 42 & $843^{\mathrm{a}}$ & 20 & UFRN & 3 & 2013 & $\mathrm{~b}$ & http://www.comperve.ufrn.br/index.php \\
Artes $^{\text {c }}$ & 11 & $204^{\mathrm{a}}$ & 18 & UDESC & 4 & 2014 & 156 & http://www.udesc.br/ceart/profartes/ \\
História $^{\text {d }}$ & 27 & $467^{\mathrm{a}}$ & 17 & UFRJ & 4 & 2013 & 88 & https://profhistoria.ufrj.br \\
Biologia & 18 & 500 & 28 & UFMG & 4 & 2016 & - & https://www.profbio.ufmg.br/organizacao/ \\
\hline
\end{tabular}

${ }^{a} \mathrm{O}$ número aparentemente exorbitante de vagas em comparação à quantidade de instituições ocorre pelo fato de algumas instituições terem mais de um campus e oferecerem o curso de forma simultânea em Unidades de ensino distintas. ${ }^{b}$ As informações de dissertações defendidas não se encontram na página do Mestrado Nacional, mas sim nas páginas de cada uma das IES participantes. ${ }^{\mathrm{c}}$ Apesar do início em 2014, só foram abertos 2 editais de seleção, sendo o segundo oferecido

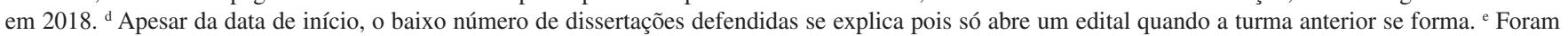
196 vagas oferecidas no primeiro semestre, e 221 vagas oferecidas no segundo semestre.

ao docente o acesso a novas propostas didático-metodológicas, utilizadas pelos professores das IES, que contribuam para a sua atuação profissional, e o amadurecimento e consolidação dos conhecimentos químicos, como ponto principal da proposta do Programa. Nesse sentido, uma pesquisa em andamento como esta, acompanhando o desenvolvimento do PROFQUI, tem muito a contribuir; ainda mais diante do papel fundamental da primeira turma e com o perfil dos pesquisadores aqui envolvidos, qual seja, do uso de tecnologias em prol da melhoria da educação.

\section{OS PRODUTOS EDUCACIONAIS DOS MPs}

Como já mencionado, uma das características dos MPs é a proposta e construção de um produto educacional voltado para atender 
as demandas que os mestrandos trazem de suas práticas profissionais locais, contribuindo não apenas com a formação docente, mas também com o processo educacional do qual esse docente faz parte, além de estreitar os laços entre pesquisa e o processo de ensino e aprendizagem.

Freire, Guerrine e $\operatorname{Dutra}^{50}$ (p. 102) definem produtos educacionais como "ferramentas pedagógicas, elaboradas pelos próprios profissionais em formação, que comportam conhecimentos organizados objetivando viabilizar a prática pedagógica". Esses proporcionam não apenas os meios de uma formação docente engajada com a pesquisa científica, mas também ferramentas viabilizadoras do transporte da pesquisa para dentro da escola. Essa é uma das articulações proporcionadas pelos MPs voltados para a formação docente, para que os docentes da educação básica possam atrelar a pesquisa ao seu cotidiano profissional e ao seu percurso formativo. Souza ${ }^{51}$ (p. 4) ainda acrescenta que

[...] Tal produto não é mera transposição didática de uma escola para a outra. Muito menos um material didático pronto para ser manipulado por professores e estudantes. Pelo contrário, é vivo, contém fluência, movimento e nunca está pronto e acabado, porque representa a dinâmica das aulas [...] vivenciada pelos estudantes.

Por isso se faz necessário que os docentes desenvolvam/adaptem produtos/recursos de acordo com as realidades dos alunos que irão utilizá-lo e o ambiente disponível para aplicação dos mesmos. A reestruturação constante permite que os discentes aproveitem ao máximo o produto/recurso educacional e contribuam na produção de conhecimento (baseados em seus conhecimentos e suas experiências únicas e pessoais) e para o aperfeiçoamento do material didático (em estrutura, em possibilidades, em dinâmicas, dentre outros).

É importante que todos tenham consciência de que os produtos educacionais desenvolvidos nos MPs voltados à formação docente, mesmo que produzidos para sanar um problema pontual do mestrando-docente-pesquisador, não podem ser vistos como "únicos e mágicos salvadores do processo educacional nacional". É preciso que não se tenha a ilusão de que o uso de uma ferramenta didática, uma única vez, transformará os alunos em "super alunos", sábios, ativos e participativos, resolvendo os problemas da escola e da comunidade.
Também ele não pode ser visto como um material que foi desenvolvido para determinada escola e permanecerá unicamente naquela escola. Como coloca Moreira ${ }^{52}$ (p. 134), é preciso que o produto educacional desenvolvido nos MPs "se constitua em material que possa ser utilizado por outros profissionais", em outros contextos, em outras instituições de ensino.

\section{PROCEDIMENTO METODOLÓGICO}

Conforme já mencionado, este artigo é parte de um estudo longitudinal em desenvolvimento, que envolve acompanhamento do PROFQUI desde a sua implantação, e consiste em uma pesquisa empírica e exploratória, de natureza quali-quantitativa. A proposta deste estudo longitudinal é investigar os três parâmetros de propostos por Gibbons e colaboradores, ${ }^{53,54}$ aplicabilidade, heterogeneidade, reflexividade. Tais parâmetros foram definidos a partir dos princípios de produção de conhecimento e dos critérios de avaliação dos Mestrados Profissionais estabelecidos pela CAPES, e são apresentados no Quadro 3, juntamente com o método de comprovação a ser empregado.

Dentro de cada um desses parâmetros, a coleta de dados utiliza três ferramentas distintas: entrevista estruturada, questionário, análise documental (Quadro 4).

Os sujeitos da pesquisa aqui apresentada foram 44 professores de Química da Educação Básica (PEBs), que matriculados no PROFQUI em sua primeira turma (no ano de 2017), e 27 professores-pesquisadores (PPs) das IES participantes do levantamento inicial. Não houve uma pré-seleção dos participantes, uma vez que o objetivo da pesquisa era levantar o quadro mais amplo possível. A participação deles ocorreu por disponibilização para participar da pesquisa, mediante uma visita realizada nas IES. Tal visita foi previamente agendada por e-mail e telefone com os coordenadores do Programa, e as IES visitadas foram previamente selecionadas de acordo com suas posições geográficas e tendo respondido positivamente ao contato inicial. Das 06 IES selecionadas, todas retornaram positivamente ao agendamento da visita, e as visitas foram realizadas em outubro e novembro de 2017. As instituições participantes (Quadro 5), que se dividem em duas regiões, nordeste e sul.

Sobre as IES selecionadas, foram levantadas algumas informações relevantes, obtidas de suas páginas oficiais:

Quadro 3. Parâmetros de investigação e metodologias de confirmação

\begin{tabular}{|c|c|c|c|}
\hline Parâmetro & Conceito & Evidência a confirmar & Método de comprovação \\
\hline APLICABILIDADE & $\begin{array}{l}\text { É o estabelecimento de compromissos } \\
\text { sólidos entre a finalidade em um con- } \\
\text { texto real e o conhecimento aplicado } \\
\text { de fato. }\end{array}$ & $\begin{array}{l}\text { O PROFQUI visa atender professores } \\
\text { de Química que atuem no ensino bá- } \\
\text { sico, e que busquem aprimoramento } \\
\text { em sua atuação profissional. }\end{array}$ & $\begin{array}{l}\text { Análise de currículo } \\
\text { Análise de impacto da avaliação dos } \\
\text { cursos por discentes e docentes } \\
\text { Análise da consonância da dissertação } \\
\text { em relação ao PROFQUI nacional } \\
\text { Análise da grade curricular }\end{array}$ \\
\hline HETEROGENEIDADE & $\begin{array}{l}\text { É heterogêneo em relação a habilida- } \\
\text { des e experiências de seus integrantes. } \\
\text { A interação ocorre em múltiplas dire- } \\
\text { ções (eletrônica, social) e em redes de } \\
\text { colaboração. }\end{array}$ & $\begin{array}{l}\text { O PROFQUI atua em rede nacional } \\
\text { e envolve sistemas como MEC, } \\
\text { CAPES, SBQ, dentre outros. } \\
\text { Utiliza um portal eletrônico próprio, } \\
\text { além de manter um Ambiente Virtual } \\
\text { de Aprendizagem (AVA), e uso de } \\
\text { videoconferência. }\end{array}$ & $\begin{array}{l}\text { Acompanhamento das áreas de atua- } \\
\text { ção (abrangência, linhas de pesquisa) } \\
\text { Visão de discentes e docentes }\end{array}$ \\
\hline REFLEXIVIDADE & $\begin{array}{l}\text { Pertinência dos conhecimentos produ- } \\
\text { zidos, aplicação e valor agregado (im- } \\
\text { pacto social). Produção de conheci- } \\
\text { mentos socialmente contextualizados }\end{array}$ & $\begin{array}{l}\text { O PROFQUI produz material didático } \\
\text { para a formação de professores para } \\
\text { que utilizem em sua prática docente } \\
\text { posteriormente. Os TCC produzidos } \\
\text { deverão ter aplicação prática, além } \\
\text { de gerar publicações nas áreas pes- } \\
\text { quisadas. }\end{array}$ & $\begin{array}{l}\text { Análise dos projetos contemplados } \\
\text { nos editais de produção de material } \\
\text { didático: submissão e relatório final } \\
\text { Análise do retorno das dissertações } \\
\text { Levantamento dos recursos tecnoló- } \\
\text { gicos disponíveis }\end{array}$ \\
\hline
\end{tabular}


Quadro 4. Ferramentas de levantamento de dados

\begin{tabular}{|c|c|c|}
\hline Entrevista & Questionário & Análise documental \\
\hline $\begin{array}{l}\text { Coordenação do } \\
\text { PROFQUI - de } \\
\text { forma presencial }\end{array}$ & $\begin{array}{l}\text { De forma presencial com: } \\
\text { - Discentes } \\
\text { - Docentes } \\
\text { De forma on-line com: } \\
\text { - Discentes } \\
\text { - Egressos } \\
\text { - Docentes }\end{array}$ & $\begin{array}{l}\text { Documentos de regula- } \\
\text { mentação analisados: } \\
\text { - Identificação do pro- } \\
\text { grama - CAPES } \\
\text { - Ofício de aprovação } \\
\text { - Regimento PROFQUI } \\
\text { - Normas acadêmicas - } \\
\text { PROFQUI } \\
\text { - Projetos de desen- } \\
\text { volvimento de material } \\
\text { didático } \\
\text { - Editais acesso } \\
\text { - Ofícios rede PROFQUI } \\
\text { - Grades curriculares } \\
\text { Produtos: } \\
\text { - Dissertações apresen- } \\
\text { tadas } \\
\text { - Projetos contempla- } \\
\text { dos no programa e seus } \\
\text { relatórios }\end{array}$ \\
\hline
\end{tabular}

- Universidade Federal do Rio Grande do Norte: é uma IES brasileira com sede na cidade de Natal, criada em junho de 1985. O PROFQUI nesta IES possui 13 docentes ativos, e a sua página oficial não possui muitas informações relevantes além das relativas ao edital de seleção 2017.

- Universidade Federal Rural de Pernambuco: é uma IES com sede em Recife, fundada em 1912. Na página desta IES não há informação específica ao PROFQUI da unidade.
- Universidade Federal de Alagoas: é uma IES com sede em Maceió, foi fundada em 1961. Sobre o PROFQUI, a página oficial da instituição não apresenta informações sobre o mestrado e nem o seu Campus.

- Universidade Federal do Paraná: Com sede em Curitiba, essa IES foi fundada em 1912, mas seu histórico de construção data de 1892, sendo considerada a mais antiga do Brasil. Assim como outras instituições acima apresentadas, essa IES não possui em sua página oficial informação sobre o PROFQUI.

- Universidade Estadual de Londrina: criada por Decreto a partida da junção de 5 faculdades em 1970, essa IES possui sede em Londrina. Os dados referentes ao PROFQUI encontram-se em área específica, sendo identificado dentro do Centro de Ciências Exatas, área Química. Contém informações de Apresentação, Informações gerais do programa, as linhas de pesquisa seguidas, a lista das disciplinas obrigatórias e suas respectivas ementas, corpo docente, dados de processo seletivo, formas de contato com a coordenação geral e a local, os horários de atendimento da secretaria, formulários referentes ao curso e um campo para dissertações defendidas (a ser preenchido conforme surgirem).

- Universidade Federal do Rio Grande do Sul: sediada em Porto Alegre, esta IES foi fundada como universidade em 1934. As informações referentes ao PROFQUI resumem-se em dados de contato e redirecionamento para a página oficial do PROFQUI.

Como ferramenta de coleta de dados, fez-se uso de dois recursos para os dois grandes grupos participantes (PEBs e PPs), conforme Quadro 6.

Neste artigo, para apresentação e discussão de dados referentes a PEBs, apenas os dados do bloco de Levantamento Social dos questionários foram utilizados. O bloco de Levantamento de Conhecimento

Quadro 5. Instituições de ensino superior visitadas no levantamento inicial

\begin{tabular}{|l|c|c|c|}
\hline \multicolumn{2}{|c|}{ Instituição } & Cidade & \multirow{2}{*}{ Data da visita } \\
\hline Nome & Sigla & Natal/RN & 16 de outubro \\
\hline Universidade Federal do Rio Grande do Norte & UFRN & Recife/PE & 18 de outubro \\
\hline Universidade Federal Rural de Pernambuco & UFRPE & Maceió/AL & 20 de outubro \\
\hline Universidade Federal de Alagoas & UFAL & Londrina/PR & 10 de novembro \\
\hline Universidade Estadual de Londrina & UEL & Curitiba/PR & 22 de novembro \\
\hline Universidade Federal do Paraná & UFPR & Porto Alegre/RS & 24 de novembro \\
\hline Universidade Federal do Rio Grande do Sul & UFRGS & &
\end{tabular}

Quadro 6. Ferramentas de coleta de dados

\begin{tabular}{|c|c|c|c|}
\hline \multirow{2}{*}{ Público alvo } & \multicolumn{3}{|c|}{ Ferramenta } \\
\hline & \multicolumn{3}{|c|}{ Questionário } \\
\hline PEBs & $\begin{array}{c}\text { Levantamento Social } \\
\text { Faixa etária, rede da graduação, área de } \\
\text { formação, rede de atuação profissional, } \\
\text { formação continuada, motivo de escolha do } \\
\text { mestrado, conhecimento a respeito da IES, } \\
\text { do MP e do PROFQUI, motivo de escolha } \\
\text { do PROFQUI, o que espera do MP, dentre } \\
\text { outras }^{\text {a }}\end{array}$ & $\begin{array}{l}\text { Levantamento de conhecimento tecnológico } \\
\text { Identificação de aparelhos de uso comum } \\
\text { no cotidiano, grau de habilidade tecnológi- } \\
\text { ca para } 26 \text { atividades relacionadas ao uso } \\
\text { de tecnologias e recursos tecnológicos }\end{array}$ & $\begin{array}{l}\text { Levantamento Profissional } \\
\text { Competência profissional e autonomia, } \\
\text { obrigação moral e autonomia, compromis- } \\
\text { so com a comunidade e autonomia }\end{array}$ \\
\hline PPs & $\begin{array}{c}\text { Levantamento Social } \\
\text { Tempo de atuação na IES, área de forma- } \\
\text { ção, atuação antes da IES }\end{array}$ & $\begin{array}{c}\text { Levantamento Técnico } \\
\text { Ingresso no PROFQUI, atuação profis- } \\
\text { sional, recursos comumente usados na } \\
\text { prática docente, contribuição na construção } \\
\text { do PROFQUI, atuação em disciplinas do } \\
\text { PROFQUI, orientações em andamento, } \\
\text { expectativas quanto ao programa }\end{array}$ & $\begin{array}{l}\text { Levantamento Didático } \\
\text { Influência na escolha dos projetos, dos } \\
\text { produtos educacionais, e dos locais de } \\
\text { desenvolvimento da pesquisa }\end{array}$ \\
\hline
\end{tabular}

aAs demais questões não são relevantes para esta discussão. 
Tecnológico, que tem por objetivo traçar o perfil tecnológico dos docentes que utilizam o PROFQUI como possibilidade de capacitação profissional e melhoria da prática docente, além de estabelecer relações entre esse perfil com a proposta de formação do Programa, está em processo de publicação. Já para dados referentes a PPs e aos Coordenadores, todos os blocos foram utilizados.

Sobre a análise dos dados, dada à estrutura dos questionários aplicados, as perguntas fechadas já possuem suas próprias categorizações, as perguntas abertas foram categorizadas através de análise de conteúdo e análise semântica. A análise de conteúdo, segundo Mayring, ${ }^{55}$ é interpretativa e ocorre por decomposição e reconstrução da ideia central do discurso para se criar categorias e identificar a dimensionalidade; já a análise semântica proporciona a criação de categorias através da avaliação do significado das respostas.

\section{O QUE SE ESPERA DO PROFQUI}

Dos PEBs participantes, dados da caracterização dos 44 PEBs que participaram do levantamento inicial ${ }^{59}$ são apresentados na Figura 2.

Estes PEBs (80\% dos participantes) possuem mais de 6 anos de experiência profissional, atuando nas redes de ensino da Figura 3. Pontuamos aqui que o somatório de indivíduos apresentados na Figura 3 não equivale ao total de participantes da pesquisa, pois um PEB pode atuar em mais de uma rede de ensino, o que ocorre para alguns dos PEBs que participaram dessa pesquisa.

Para a grande maioria (93\%) a formação em nível de graduação é em Licenciatura em Química. Ainda sobre formação, os PEBs indicaram a busca por especializações para suprir algumas necessidades profissionais, e dois PEBs já cursaram um mestrado acadêmico; para todos os demais, o PROFQUI é o primeiro curso stricto sensu cursado. Esse perfil profissional, de buscar cada vez mais conhecimento (específico, didático, prático e técnico) através de cursos de especialização e formação continuada, tem se tornado cada vez mais necessário, dada a importância e papel do professor nas políticas educacionais. As motivações indicadas pelos PEBs constam, em sua maioria, de interesse em melhorar a qualificação profissional (75\%) e em aumentar a remuneração salarial (12\%).

Em análise às demais respostas da caracterização profissional do questionário dos PEBs, outro fator levantado foi a busca pela capacitação e como chegou ao PROFQUI. Quando questionados sobre o conhecimento a respeito de MP, 39\% não sabia o que era um MP. Apesar de não ser a maioria, é possível fazer uma breve reflexão a respeito da difusão dos MPs na sociedade e no próprio meio acadêmico. Ribeiro ${ }^{56}$ afirma que "[...] o MP voltado à formação de professores, [...] conta com maior oposição da área de Educação" (p. 13); enquanto que Moreira e $\mathrm{Nardi}^{57}$ apontam alguns problemas dos MP em andamento, como "[...] de estrutura curricular, com relação à definição de produção técnica e até mesmo de identidade, enquanto que algumas das novas propostas os confundem com variantes dos mestrados acadêmicos ou até mesmo de cursos de especialização" (p. 2). Esses são alguns dos fatores que podem justificar esse resultado a respeito do conhecimento sobre MP na sociedade e na comunidade acadêmica; a própria construção da identidade do Programa bem como a compreensão da sua finalidade para a formação docente (pelos pares e pelos próprios docentes participantes) são obstáculos auto infligidos a sua existência e desenvolvimento. Este índice se completa com a próxima pergunta do questionário. Quando questionados mais especificamente se conheciam o PROFQUI antes de fazer a inscrição, $86 \%$ indicaram que pesquisaram para conhecer (pois não conheciam) ou tirar dúvidas

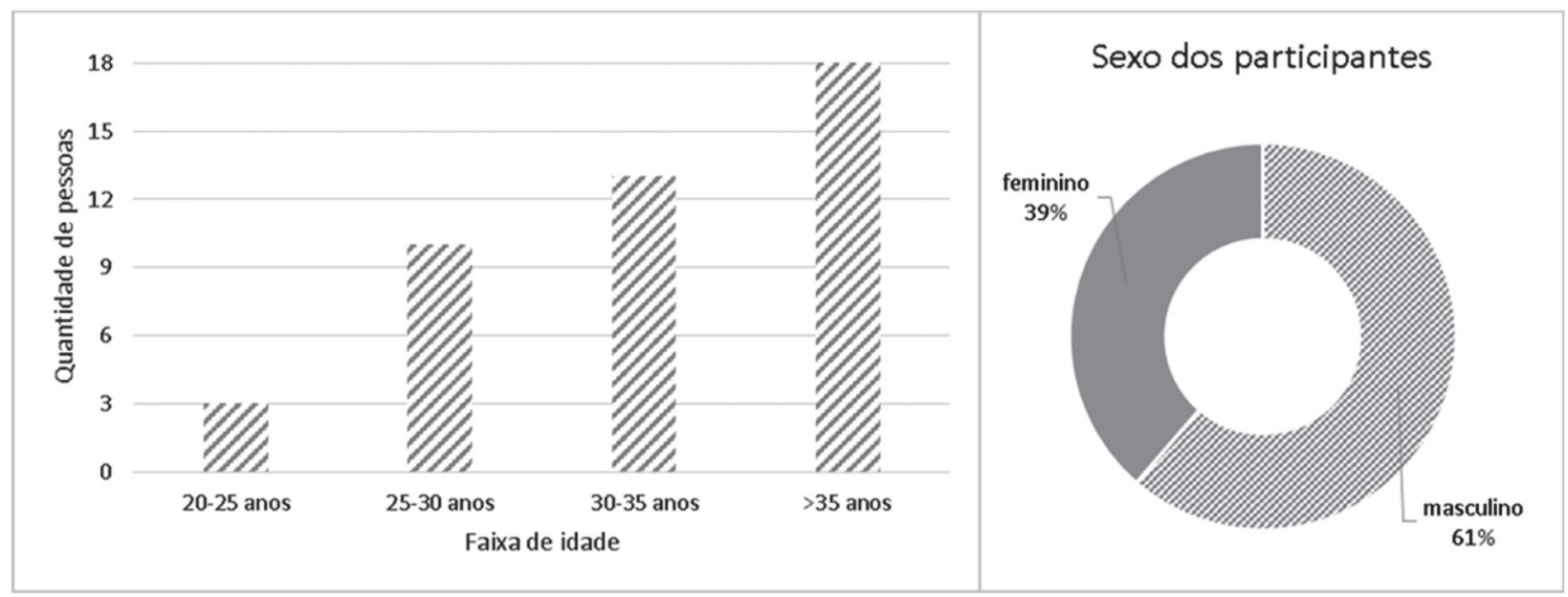

Figura 2. Faixa etária e sexo dos participantes

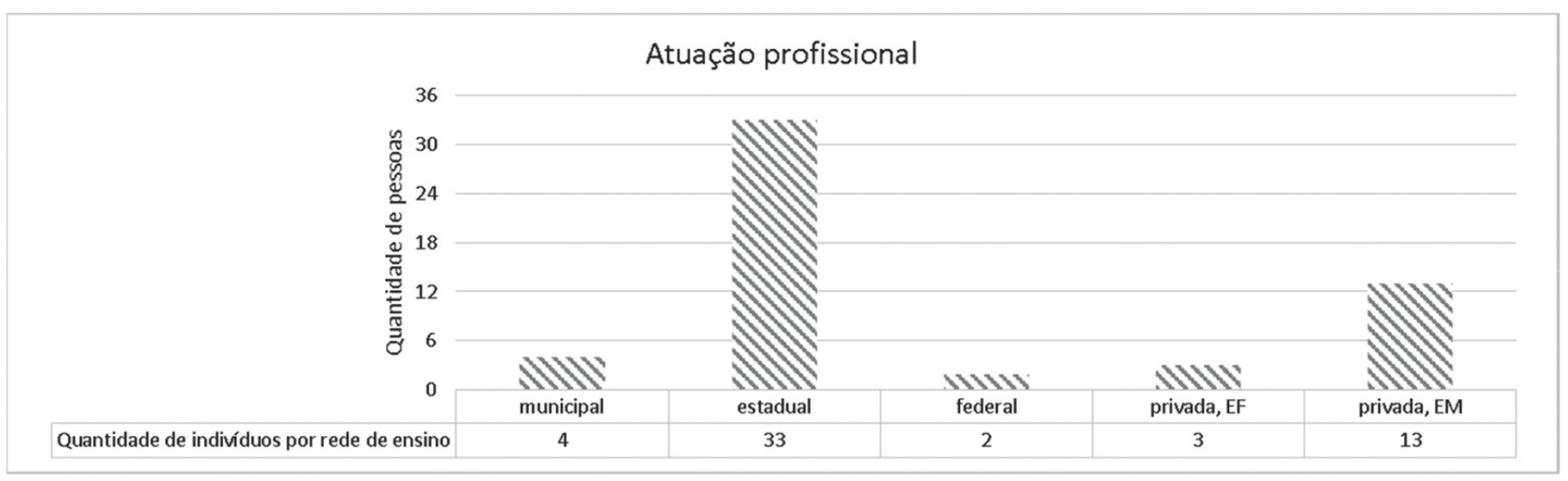

Figura 3. Rede de ensino de atuação dos participantes 
(pois conheciam outros PROFs), 7\% já conheciam a proposta do MP, e $9 \%$ não tiveram interesse em pesquisar, apenas se inscreveram, pois eram da área de interesse (Química).

Os participantes também foram questionados sobre o que os levou a escolher um MP ao invés de um MA. Todos os PEBs da pesquisa indicaram a busca por este MP como uma forma de ampliar suas qualificações profissionais juntamente com a melhoria da sua prática docente. Esse anseio se registra nas apresentações das motivações como "o mestrado profissional como é na área de ensino terá mais contribuições para a docência do que o mestrado acadêmico, principalmente em metodologias de ensino, conceitos na área de ensino, teorias...", do PEB_VLO, ou como "O mestrado profissional é mais focado na atuação do professor”, do PEB_GPR, ainda como "O que motivou-me foi a possibilidade/viabilidade de transpor aos conhecimentos construídos ao longo do programa na minha atuação profissional. Creio que a aplicabilidade deste tipo de programa é maior", do PEB_MR. De forma geral, as motivações dos 44 PEBs podem ser divididas e apresentadas conforme Figura 4.

Mesmo que não haja uma clareza de objetivos (ou seja do ponto exato onde querem chegar), pode-se dizer que apresentam um início de pensamento crítico com relação ao processo de ensino e a sua prática profissional. E esse pensamento crítico precisa ser amadurecido ao longo do MP para que o profissional formado possa ser mais/ melhor atuante em sua comunidade e na sua profissão.

Quanto aos PPs participantes, diferente do que ocorre para os PEBs, a maioria é de mulheres (59\%), estando a maior parte destas atuando na região nordeste (11 de 16 mulheres).

As caracterizações de área de formação a nível de doutorado são variadas, com uma leve predominância da Química Orgânica, e o tempo de experiência profissional para a maioria é de mais de 10 anos, como representados na Figura 5. Pontuando que para as áreas

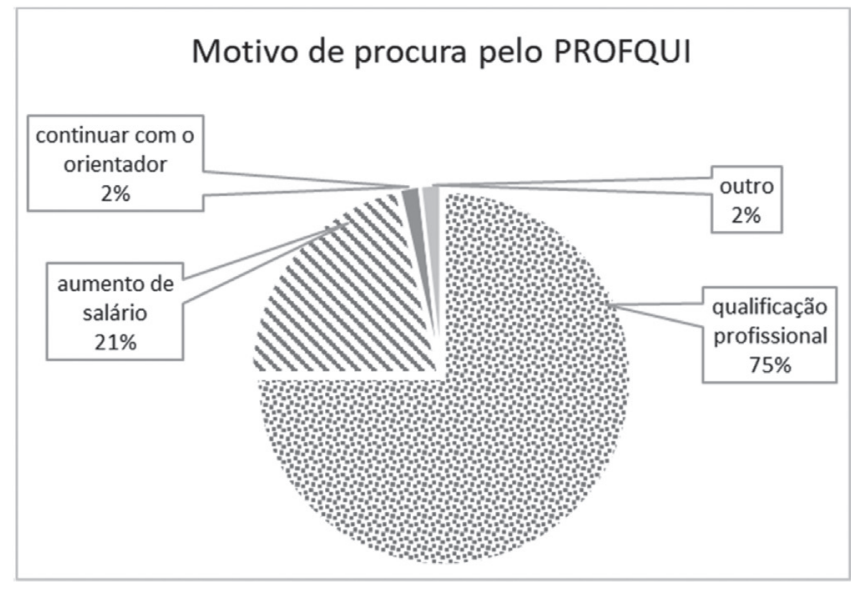

Figura 4. Motivo de procura pelo PROFQUI

de doutoramento o somatório ultrapassa os $100 \%$ devido a um mesmo PPs informar dois doutorados em áreas distintas.

A formação distinta do corpo docente pode permitir aos PEBs uma maior experiência de conhecimento específico e de atuação profissional e instrumentação em sala de aula, desde que a forma de lecionar siga as previsões contidas nos documentos norteadores do Programa.

Como uma forma de identificar os PPs e suas experiências antes do PROFQUI, os mesmos foram questionados sobre suas atuações antes de ingressar em suas atuais IES. As respostas indicam um amplo leque de atuações (Figura 6), que ultrapassam os $100 \%$ devido a atuação de um mesmo indivíduo em mais de uma esfera. A indicação de "outro" dentro das alternativas, foi apontada por todos os respondentes como atuação na indústria química.

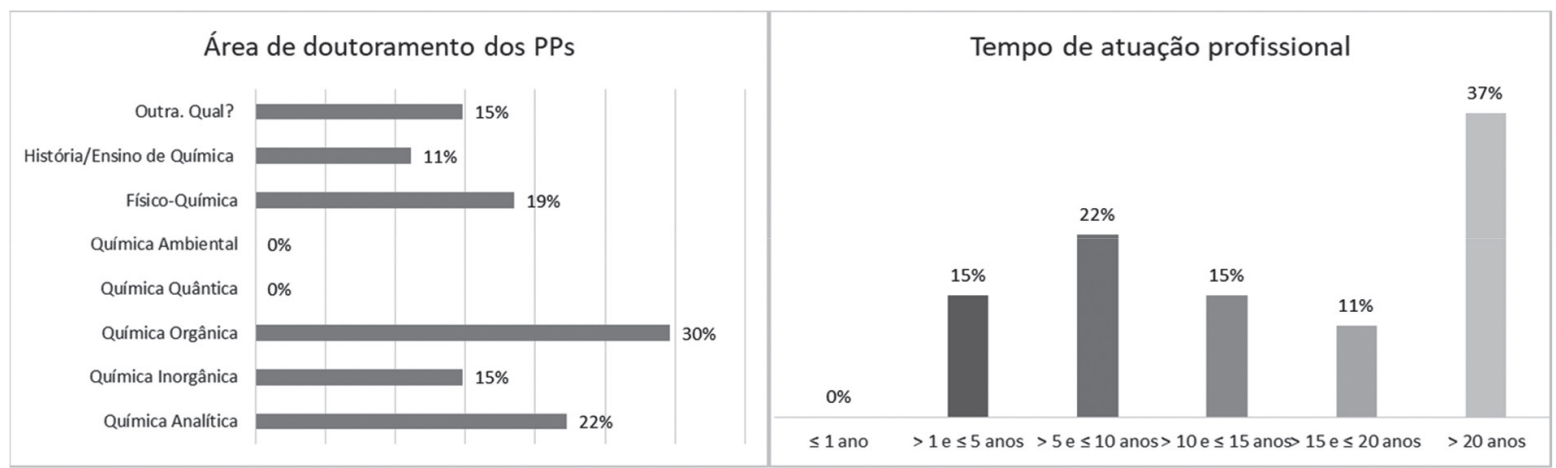

Figura 5. Área de doutoramento e tempo de atuação profissional dos PPs

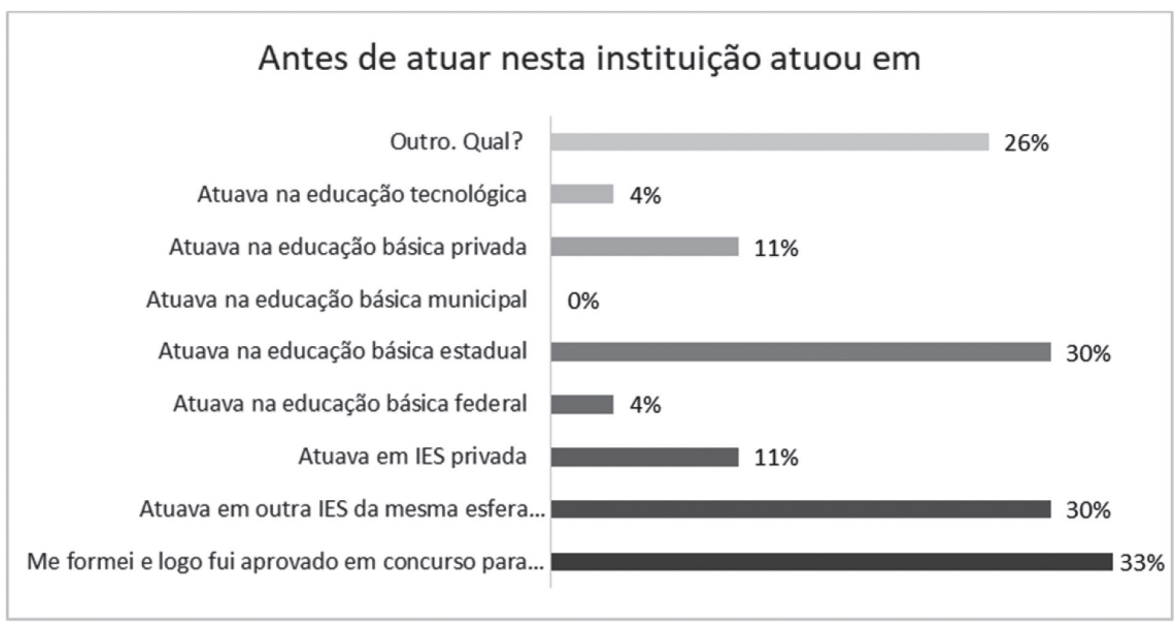

Figura 6. Atuação dos PPs antes do ingresso na atual IES 
Tais atuações representam, para 67\% dos PPs, experiências com outros níveis de ensino, de forma direta ou indireta, antes da atuação na atual IES e no PROFQUI, o que pode impactar de maneira construtiva e positiva a participação destes PPs na formação dos PEBs participantes do Programa. Quando questionados sobre as atuais atuações dentro da IES, os PPs indicaram que atuam em vários níveis em suas instituições; não apenas na graduação presencial (96\% dos PPs) e à distância (33\% dos PPs), mas também em especializações presenciais $(7 \%)$ e à distância $(7 \%)$, em outro MP (11\%), em MA e DA do mesmo instituto (11\%) ou de outro instituto (33\%). Essas diferentes experiências têm potencial para enriquecer o programa, quando utilizadas de forma construtiva na formação dos PEBs participantes e/ou orientados.

Sobre a origem de participação no PROFQUI, um PP que não compusesse a equipe inicial de implantação do Programa poderia ingressar, de duas formas: sendo convidado pela coordenação (equipe coordenadora) ou se candidatando voluntariamente a participar do Programa. Os PPs que participaram desta pesquisa indicaram que $41 \%$ foi convidado pela coordenação para compor o quadro docente, e que $37 \%$ se candidataram a vaga no quadro docente do Programa. Independente da forma de ingressos, todos os PPs participantes informaram atuação dentro do PROFQUI, seja através da condução de disciplinas (que, por serem poucas, acabam sendo dividas entre 2 ou 3 PPs - 74\% dos PPs divide disciplinas com outros docentes) ou através da orientação de PEBs (41\% dos PPs iniciou uma orientação). Como o levantamento destes dados em 2017 ocorreu no meio do primeiro semestre de implantação do Programa, e a escolha de orientadores ocorre no final do primeiro semestre, nem todos os PPs estavam com orientações iniciadas, devido ao pouco tempo de contato com os PEBs; por isso o baixo índice de PPs com orientações iniciadas.

As questões referentes a relação com o orientando se dividem em três questões: sobre a escolha do tema, sobre a condução do projeto, e sobre a escolha do produto educacional; sendo as respostas apresentas no conjunto de gráficos que constitui a Figura 7.

É possível notar através deste resultado que 63\% dos PPs receberam propostas de projetos factíveis por parte os PEBs, demonstrando potencial para o desenvolvimento de boas pesquisas relacionadas ao cotidiano escolar e às suas atividades docentes. Um ponto que cabe destaque é que um MP voltado para a formação de professores requer que os trabalhos desenvolvidos tenham por palco de pesquisa o local de trabalho do PEB, o que pode fazer com que os $7 \%$ dos PPs que buscam outra instituição para o desenvolvimento dos projetos mudem seu posicionamento. As informações coletadas com estas questões permitem apontar um bom ambiente de desenvolvimento acadêmico para que as pesquisas sejam concluídas satisfatoriamente.

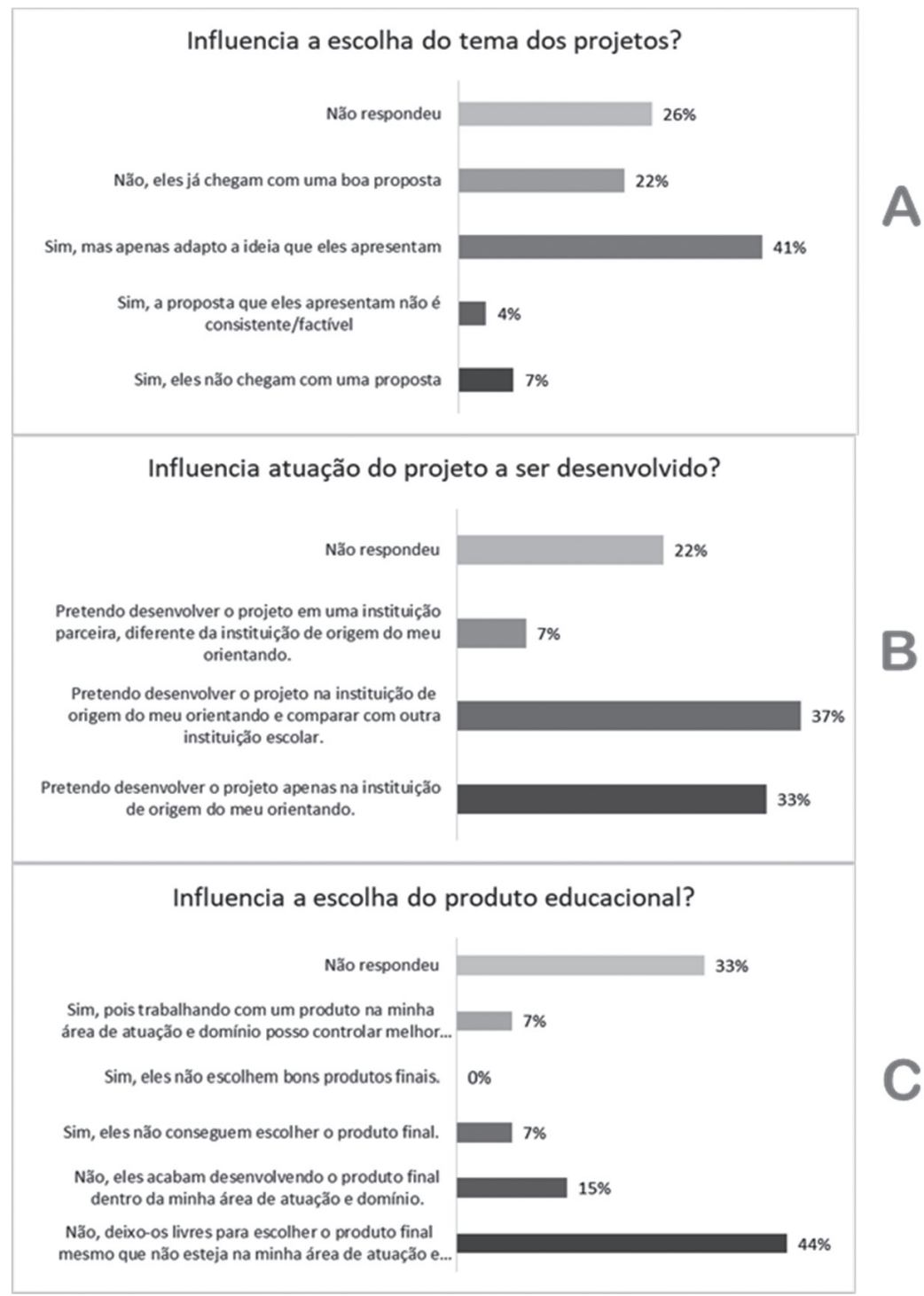

Figura 7. Influência nas escolhas do projeto dos PEBs 
A respeito dos recursos didáticos comumente utilizados pelos PPs, o uso é bastante diversificado (Figura 8), porém ainda com a predominância do uso de livros e de artigos científicos. Mesmo que algumas das opções tenham um uso diminuto e pontual para alguns docentes, é importante pontuar que, por um lado se torna um tímido estímulo para os PEBs, através da percepção de uma possibilidade de abordagem diferenciada.

Sobre as expectativas docentes, houve um anseio quanto ao desdobramento do Programa devido a sua novidade, uma vez que se iniciou em 2017 (mesmo possuindo estrutura semelhante a outros MP que já existem e estão em funcionamento), e devido a sua importância e impacto nas comunidades alcançadas através dos discentes participantes. Os docentes indicam que também aguardam a ampliação do Programa para um melhor desenvolvimento dele, seja em currículo ou estrutura.

Houve uma expectativa geral, de PPs e PEBs, quanto ao desenvolvimento do produto educacional, requisito parcial para aprovação no Programa. Surgiram de ambas as partes a dúvida sobre o que consiste um produto educacional, e um anseio em definir qual será o produto a ser desenvolvido. Com relação aos PPs, há uma compreensão maior do que sejam os produtos educacionais (as possíveis modalidades), mesmo que não conheçam as especificidades de todas as produções. Parte dos PEBs mostraram uma definição da forma, mas não da dinâmica (ou seja, definiram o "o quê?", mas não definiram o “como?”) do produto educacional que será desenvolvido, mas outros alunos, na época do levantamento, ainda tinham dúvidas sobre o que gostariam de desenvolver, já que entraram no MP para conhecer recursos e metodologias.

Esse é um ponto que requer maiores esforços por ambas as partes para que sejam desenvolvidos produtos de qualidade que sejam aplicáveis e realmente úteis aos PEBs em suas atividades laborais. O PROFQUI não oferece uma disciplina que proporcione esse tipo de discussão (desenvolvimento de recurso educacional), uma vez que seu foco é o desenvolvimento científico do professor de química, e não o desenvolvimento didático-pedagógico; e essa ausência, além de empobrecer a formação docente, pode ocasionar um obstáculo no processo criativo de construção dos produtos educacionais de uma área tão rica de possibilidades, como a Química.

É importante tratar com atenção os produtos educacionais a serem desenvolvidos dentro do PROFQUI, não apenas no seu desenvolvimento (como já se espera), mas também na sua disponibilização, uma vez que a divulgação científica também faz parte do processo educativo, tanto na IES quanto na escola. Além disso, os produtos educacionais dentro desta área são de uma vasta extensão de possibilidades e dificuldades devido ao grau de riqueza e abstração das informações trabalhadas, e um preparo do docente para o desenvolvimento desses materiais seria amplamente valioso não só para o aumento do protagonismo docente, mas também para os alunos da educação básica.

\section{CONSIDERAÇÕES FINAIS}

No atual quadro educacional, o docente vem sendo cada vez mais cobrado e menos preparado em sua formação em nível de graduação para a atuação profissional. É exigido do docente lecionar o conteúdo, organizar situações de aprendizagem, promover situações que permitam que os alunos transitem entre o senso comum e o conhecimento científico, inserir o aluno tecnologicamente, conscientizar ambientalmente, preparar socialmente, dentre outras funções acumulativas em sua jornada de trabalho. Ainda sobre a atuação docente, Kuenzer ${ }^{58}$ (p. 686) coloca que o docente deve "suprir, em uma escola precarizada, com condições de trabalho cada vez piores, as deficiências culturais e cognitivas decorrentes da origem de classe da maioria dos alunos".

A formação do professor reflexivo não valerá a pena se não envolver a formação docente na luta contra a atual situação política e econômica. ${ }^{59} \mathrm{~A}$ formação continuada está inserida em um cenário de

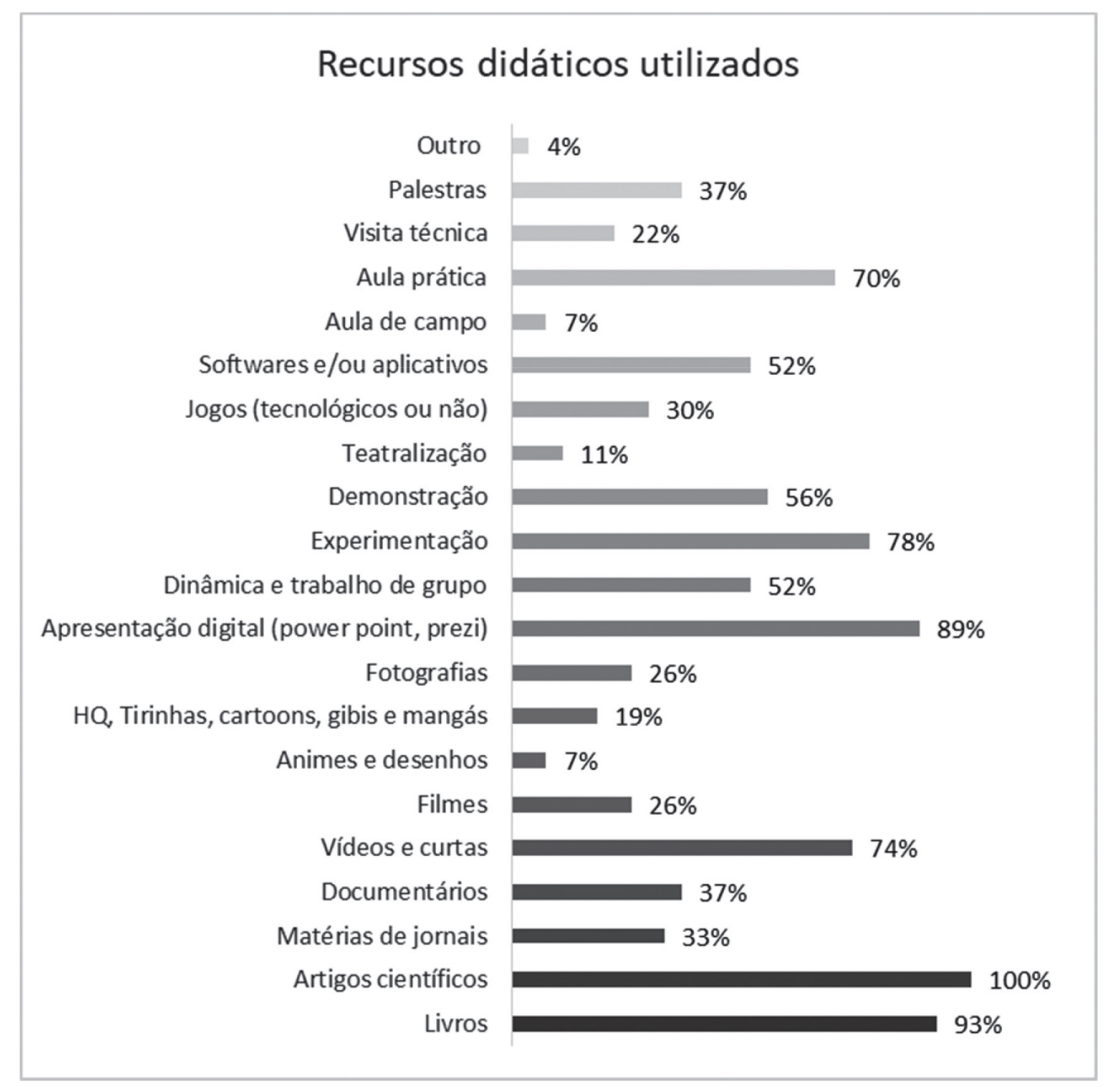

Figura 8. Recursos didáticos comumente utilizados pelos PPS 
desvalorização da atividade docente; devido à fragmentação das ações nas políticas públicas de formação profissional do magistério. ${ }^{60,61}$ Apesar de todos os esforços e compreensão de fatos, o texto apresentado no decreto que institui a Política Nacional de Formação de Profissionais do Magistério da Educação Básica (decreto 6755/09) ${ }^{41}$ não expressa claro entendimento de que um dos requisitos básicos para a educação de qualidade seja a valorização docente.

A formação continuada se tornou um pré-requisito para uma transformação docente mais pronunciada, devido às oportunidades que surgem ao docente durante o processo de formação para vivenciar pesquisas e experiências que podem ser aplicadas em sua atuação profissional. Porém, cabe destacar que apesar dos benefícios e atuações da formação continuada, uma boa formação em nível de graduação (e a melhoria do atual processo) ainda é importante. ${ }^{62}$

Vários estudos sobre as tendências atuais na formação continuada apontam a necessidade de eleger a escola como lócus privilegiado dessa formação, ${ }^{63}$ articulando a formação no próprio local de trabalho, elaborando um projeto coletivo com participação da comunidade escolar para articular a prática pedagógica. O objetivo de fazer da escola o ambiente da formação não é usar os problemas da escola como origem da formulação dos objetivos do MP, mas proporcionar o domínio de novos conhecimentos, melhorando a EB.

É importante ter o MP como foco de estudos para que as contribuições da sua proposta de atuação e seu formato sejam verificados, bem como seus reflexos na melhoria na qualidade da educação básica sejam efetivadas. É justamente isso que justifica o projeto de acompanhamento do PROFQUI, ora em curso. Nesse sentido, neste artigo, buscamos promover a reflexão que já ocorre em outros MPs voltados para a formação docente, sobre o aperfeiçoamento da atuação docente através da formação continuada dos professores de Química e sobre os produtos educacionais por eles desenvolvidos. Além disso, é importante que os MPs estejam em constante adaptação para que continuem atendendo às necessidades da educação básica dentro de suas especificidades (quando capacitam esses docentes de forma direcionada), pois só através da reflexão e das discussões é que essa adaptação é passível de ocorrer.

Em observação aos dados apresentados, a titulação do corpo docente permanente dos PPs do PROFQUI, participantes desta pesquisa, associada fortemente à Química Acadêmica, e dos recursos didáticos utilizados pelos mesmos serem basicamente livros, artigos científicos e aulas em softwares de apresentação pode, em alguns aspectos, ser favorável a construção do conhecimento químico, mas também pode ser desfavorável à construção de um PEBs enquanto professor-pesquisador da sua prática profissional e mediador da construção do conhecimento dos alunos da educação básica. A formação de um docente realmente capacitado em suas atividades laborais depende de diversos aspectos além do "saber o conteúdo". Foi possível notar, com o levantamento, que os PEBs esperam a construção de melhorias no desenvolvimento profissional para o Ensino de Química. Essas melhorias versam não apenas sobre a atualização científica em Química, mas também sobre recursos didáticos e possíveis práticas/ atividades que contribuam com a sua atuação profissional. E todos esses pontos estão presentes e são incentivados pelos documentos norteadores da educação e pela evolução da sociedade.

Algumas dessas possibilidades efetivas de construção profissional dos PEBs podem não ser totalmente supridas pelo programa, uma vez que o mesmo foca na atualização dos conhecimentos químicos e não na formação didático-pedagógica do docente para o ensino de Química, o que pode ser percebido não apenas em seu regimento, mas também em sua matriz curricular ou mesmo pela formação docente dos PPs participantes da pesquisa e seu tímido uso de recursos didáticos mais variados. É necessário que, mesmo que o foco do Programa seja o desenvolvimento de conteúdo específico, a abordagem desse conteúdo fomente, também, as necessidades dos alunos da educação básica, e não apenas foque na atualização científica do professor de Química. Os objetivos enunciados pelo PROFQUI precisam se materializar e evidenciar em toda a sua estrutura; um bom passo é a existência de LP que abordem conhecimento específico e metodologias e recursos diversificados; porém, os PPs que as constituem devem se adaptar a essa proposta metodológica dento das respectivas LP. Talvez esse seja um obstáculo para o desenvolvimento do programa ao longo dos anos, assim como foi para outros programas no âmbito do ProEB, como o PROFMAT. ${ }^{64}$

Como próximas etapas desse estudo longitudinal, pretende-se continuar o levantamento de dados e documentos relacionados direta e indiretamente ao programa, apresentados nos Quadros 3 e 4, sendo esses analisados por estatística básica, análise textual discursiva e modelagem ontológica, visando confirmar, ou não, a aplicabilidade, a heterogeneidade e a reflexividade do PROFQUI enquanto proposta de formação continuada em Química para professores no ensino de Química da educação básica.

\section{AGRADECIMENTOS}

Ao CNPq pelo fomento do início do projeto, Processo número 458724/2014-9.

\section{REFERÊNCIAS}

1. Becker, F.; Educação e Construção do Conhecimento. Porto Alegre: Penso, 2012.

2. Gasparini, A. R.; Dissertação de Mestrado, Universidade de São Paulo, Brasil, 2008.

3. Piaget, J.; Biologia e Conhecimento. Vozes: Petrópolis, 1996.

4. Montangero, J.; Maurice-Naville, D.; Piaget ou a inteligência em evolução. Porto Alegre: Artmed, 1998.

5. Ghedin, E.; Almeida, M. I. de; Leite, Y. U. F.; Formação de professores: caminhos e descaminhos da prática. Brasília: Liber, 2008.

6. Gratiot-Alfandéry, H.; Henri Wallon, Recife: Fundação Joaquim Nabuco, Editora Massangana, 2010.

7. http://inep.gov.br/web/guest/censo-da-educacao-superior, acessada em Fevereiro 2020.

8. Mesquita, N A. da S.; Soares, M. H. F. B.; Quim. Nova 2011, 34, 165.

9. Frigotto, G.; Ciavatta, M.; Ensino Médio: ciência, cultura e trabalho, MEC, SEMTEC: Brasília, 2004.

10. Pereira, J. E. D.; Educ. Soc. 1999, 20, 109

11. de Freitas, H. C. L.; Educ. Soc. 2002, 23, 136.

12. Schnetzler, R. P.; Quim. Nova 2002, 25, 14.

13. Imbernón, F.; Formação Continuada de Professores. Porto Alegre: Artmed, 2010.

14. https://capes.gov.br/publicacoes/artigos/4721-a-capes-e-a-educacaobasica, acessada em Fevereiro 2020.

15. Pimenta, S. G.; Lima, M. S. L.; Estágio e Docência, São Paulo: Cortez, 2012.

16. Silva, K. C. M. O.; Mesquita, N. A. S.; Quim. Nova Esc. 2018, 40, 44

17. Sistemas colaborativos; Pimentel, M., Fuks, H., eds.; Elsevier Brasil: Rio de Janeiro, 2012.

18. Quién educará a los educadores? Teoría y práctica de la formación de formadores; Vaillant, D., Marcelo, C. G., orgs.; Productora Editorial: Montevideo, 1998.

19. Vaillant, D.; Marcelo, C. G.; Ensinando a ensinar: as quatro etapas de uma aprendizagem, Ed. UTFPR: Curitiba, 2012.

20. Wang, J.; Lin, E.; Spalding, E.; Klecka, C. L.; Odell, S. J.; Journal of Teacher Education 2011, 62, 331.

21. Beillerot, J. A. Em O papel da pesquisa na formação e na prática dos professores; André, M., ed.; Papirus: Campinas, 2001. 
22. Justino, M. N.; Pesquisa e recursos didáticos da formação e prática docentes, InterSaberes: Curitiba, 2013.

23. Machado, N. J. Em As competências para ensinar no Século XXI: a formação dos professores e o desafio da avaliação; Perrenoud, P., Thurler, M. G., de Macedo, L., Machado, N. J., Allessandrini, C. D., orgs.; Artmed Editora: Porto Alegre, 2002.

24. Pena, G.A.C.; Dissertação de Mestrado, Universidade Federal de Minas Gerais, 1999.

25. Leal, M. C.; Dissertação de Mestrado, Universidade Federal de Minas Gerais, 2003.

26. Leal, M. C.; Mortimer, E. F.; Ciênc. Educ. (Bauru) 2008, 14, 213.

27. https://www.capes.gov.br/educacao-a-distancia/proeb, acessada em Setembro 2019.

28. Maués, O. C.; Camargo, A. M. M.; Revista Educação em Questão 2012, $42,28$.

29. Brasil; Portaria $n^{\circ}$ 80, 16 de dezembro de 1998, disponível em https:// abmes.org.br/legislacoes/detalhe/2183/portaria-capes-n-80, acessada em Fevereiro 2020.

30. Ribeiro, R. J.; Revista Brasileira de Pós-Graduação 2006, 3, 6.

31. Fischer, T.; Revista Brasileira de Pós-Graduação 2005, 2, 24.

32. Melo, K. V. A.; Oliveira, R. R.; Revista Brasileira de Pós-Graduação 2005, 2, 105.

33. Ribeiro, R. J.; Revista Brasileira de Pós-Graduação 2005, 2, 4.

34. Hetkowski, T. M.; PLURAIS - Revista Multidisciplinar 2016, $1,1$.

35. Almeida Junior, A.; Sucupira, N.; Salgado, C.; Barreto Filho, J.; Silva, M. R.; Trigueiro, D.; Lima, A. A.; Teixeira, A.; Chagas, V.; Maciel, R.; Rev. Bras. Educ. 2005, 30, 162.

36. Ostermann, F.; Rezende, F.; Caderno Brasileiro de Ensino de Física 2009, 26, 66

37. Nunes, B. T.; Tese de Doutorado, Universidade Católica de Brasília, Brasília, 2017.

38. http://avaliacaoquadrienal.capes.gov.br/home, acessada em Julho 2017.

39. http://www.brasil.gov.br/educacao/2015/04/conheca-programas-demestrado-profissional-recomendados-pela-capes, acessada Fevereiro 2020.

40. Brasil, Portaria Normativa no 7, de 22 de junho de 2009. https://abmes. org.br/legislacoes/detalhe/2075/portaria-normativa-n-7, acessada em Fevereiro 2020.

41. Brasil, Portaria Normativa $\mathrm{n}^{\circ} 17$, de 28 de dezembro de 2009 , disponível em https://abmes.org.br/legislacoes/detalhe/2074/portarianormativa-n-17, acessado em Fevereiro 2020
42. http://portal.mec.gov.br/component/content/index.php?option=com_co ntent $\&$ view=article $\&$ id=51411 :programas-de-pos-graduacao-ganhamavaliacao-quadrienal\&catid=212\&Itemid=86, acessada em Julho 2017.

43. https://profqui.iq.ufrj.br/, acessado em Fevereiro 2020.

44. Brasil. Lei no 13.005, de 25 de junho de 2014, disponível em http://www. planalto.gov.br/ccivil_03/_ato2011-2014/2014/lei/113005.htm, acessada em Fevereiro 2020.

45. Scheibe, L.; Educ. Soc. 2010, 31, 112.

46. Oliveira, D. A.; Revista Educação em Questão 2013, 46, 51.

47. Hypolito, A. L. M.; Cad. CEDES 2015, 35, 517.

48. Oliveira, D. A.; Retratos da Escola 2015, 8, 447.

49. Piolli, E.; Cad. CEDES 2015, 35, 97.

50. Freire. G. G.; Guerrini, D.; Dutra, A.; Revista Porto das Letras 2016, 02, 100 .

51. de Sousa, M. do C.; Resumos do II Encontro da rede de professores, pesquisadores e licenciandos de Física e de Matemática, São Carlos, Brasil, 2010.

52. Moreira, M. A.; Revista Brasileira de Pós-Graduação 2004, 1, 131.

53. Gibbons, M.; Limoges, C.; Nowotny, H.; Schwartzman, S.; Scott, P.; Trow, M. The new production of knowledge: the dynamics of science and research in contemporary societies, Sage Publications: London, 1994.

54. Gibbons, M.; Limoges, C.; Nowotny, H.; Schwartzman, S.; Scott, P.; Trow, M.; La nueva producción del conocimiento: la dinámica de la ciencia y la investigación en las sociedades contemporáneas. Ediciones Pomares-Corredor S. A.: Barcelona, 1997.

55. Mayring, P.; Qualitative Inhaltsanalyse, Springer: Berlim, 2010.

56. Ribeiro, R. J.; Revista Brasileira de Pós-Graduação 2005, $2,8$.

57. Moreira, M. A.; Nardi, R.; Revista Brasileira de Ensino de Ciência e Tecnologia 2009, 2, 1 .

58. Kuenzer, A. Z.; Educ. Soc. 2011, 32, 667.

59. Zeichner, K. M.; Educ. Soc. 2008, 29, 535.

60. Scheibe, L.; Cad. Pesqui. 2011, 41, 812.

61. Rezende, F.; Ostermann, F.; Ciênc Educ. (Bauru). 2015, 21, 543.

62. Chimentão, L. K.; Anais do $4^{o}$ Congresso Norte Paranaense de Educação Física Escolar, Londrina, Brasil, 2009.

63. Lage, M. A. G.; Urzetta, F. C.; Cunha, A. M. de O.; Anais do VIII Encontro Nacional de Pesquisa em Educação em Ciências, Campinas, Brasil, 2011.

64. Caldatto, M. E.; Pavanello, R. M.; Fiorentini, D.; Boletim de Educação Matemática 2016, 30, 906. 